Aprendizados com a diferença

\section{em uma}

experiência da paternidade:

\section{do testemunho ao cuidado}

\section{Aprendizajes con la diferencia en una experiencia de paternidad: del testimonio al cuidado}

\author{
Learning with a difference in an \\ experience of paternity: \\ from testimony to caring
}

\section{Pedro Angelo Pagni}

* Profesor Asociado de Filosofia de la Educación del Departamento de Administração e Supervisão Escolar y del Departamento de Pósgraduação em Educação de la Universidade Estadual Paulista Júlio de Mesquita Filho (São Paulo - Brasil), Diretor del Grupo de Trabajo Filosofia e Educação de ANPEd. Graduado en Educación Física de la Universidade Estadual Paulista Júlio de Mesquita Filho (1987), Magister en Historia y Filosofía de la Educación de la Pontifícia Universidade Católica deSão Paulo (1994), DoctorenEducación(1999). Correo electrónico: pagni@terra.com.br

El presente artículo es un producto del proyecto de investigación: "Ética, acontecimiento y pragmática de sí: desafíos de la arte de vivir a la educación", financiado por el CNPq.

\section{Resumen}

Este ensayo narra una experiencia singular de paternidad, de las relaciones de un padre con su hija y del cuidado aprendido con un niño con necesidades especiales. Son narradas las propias transformaciones del autor, usando los recursos teóricos que marcaron su trayectoria intelectual y los límites de los mismos para analizarla. Se establece un contrapunto con el discurso de la inclusión y los saberes especializados, en la perspectiva de un acontecimiento discursivo que produzca un pensar filosófico y aprendizaje con la diferencia capaz de promover la auto-transformación de los sujetos que actúan en ese campo en su acción educativa.

\section{Palabras clave}

Experiencia, diferencia, cuidado, testimonio.

\section{Resumo}

Este ensaio narra uma experiência singular de paternidade, das relações de um pai com sua filha e do cuidado aprendido com uma criança com necessidades especiais. São narradas as próprias transformações do autor, usando os recursos teóricos que marcaram a sua trajetória intelectual e os limites dos mesmos para analisá-la. Estabelece-se um contraponto com o discurso da inclusão e dos saberes especializados, tendo em vista um acontecimento discursivo que produza um pensar filosófico e um aprendizado com a diferença capaz de promover a autotransformação dos sujeitos que atuam nesse campo em sua ação educativa.

\section{Palavras chave}

Experiência, diferença, cuidado, testemunho.

\section{Abstract}

This essay tells a singular experience of paternity, a parent's relationship to his daughter and learning of a child with special needs. This narrated experience has as an objective of the author's own narration of the transformations of this test, the theoretical features that marked his intellectual trajectory and limits them to express it. From this perspective, this essay seeks to give voice to this unique experience of caring with the goal of establishing a counterpoint with the discourse of inclusion and the specialized knowledge, with a view to a discursive event that produces a philosophical thinking and an apprenticeship with the difference that can promote the self-transformation of individuals who act in this field in their educational action.

\section{Key words}

Experience, difference, caution, testimony.

Fecha de recepción: 28 de marzo de 2012 Fecha de aprobación: 10 de agosto de 2012 .............................................. 
$\mathrm{U}$ $m$ dia deitei-me no divã e disse à terapeuta: "Sempre te disse que era uma pessoa afortunada, acho que as coisas começaram a mudar. Minha filha, por quem tanto esperei, nasceu com síndrome de Down". Algum tempo depois, cerca de um ano, já voltava a me sentir alguém afortunado novamente, talvez, até mais do que antes. Afinal, dizia eu a mesma terapeuta: "Minha filha mudou minha vida, deu-me o que nunca tive -um pouco de humanidade, orgulho do que sou com todos meus defeitos e, principalmente, de ser pai dela, com tudo aquilo que possa ser de diferente".

Desde que ela nasceu sinto-me em devir e com uma dívida semelhante à dívida para com a infância a qual se refere Lyotard (1997), porém, com uma infância particular a qual procuro saudar por meio de uma escrita e de um gênero de testemunho. Talvez, não saiba muito bem sua origem, tampouco entenda o porquê, mas sinto-me em dívida com o que aprendi com minha filha ao ponto de achar que essa experiência com ela deva ser narrada, pois, mais do que aprender somente com ela pude olhá-la de outro modo a partir das várias narrativas de experiências de pais de crianças e jovens com trissomia, destas mesmas crianças e jovens que ouvi em alguns documentários, todas elas, hoje noto, diferentes da que vivi e vivo. Mas foi nesse contraste de narrativas que pude pensar e narrar a minha experiência de paternidade, na forma de um ensaio que mistura autobiografia e, como todas do gênero, ficção.

Este ensaio não procura, assim, elaborar o dolo da perda irreparável de uma filha real, como o faz Pierre Péju (2004), nem o luto de uma ideia de filha que se vai elaborando na medida em que se convive com ela, como expresso no início do documentário Do luto à luta de Evaldo Mocarzel, tampouco o processo de autoconhecimento que se vai estabelecendo como pai na relação com o filho nascido com trissomia, como o romance de Ricardo Tezza (2008), e muito menos se refere ao processo de ver na relação de amizade com alguém tão diferente um encontro que faz com que um amigo se transforme, restabelecendo outros sentidos à sua vida, como estabelecidos no filme Huitième Jour de Jaco Van Dormael. Essas narrativas apreendem um pouco de tudo que narro aqui e de nada do que foi experienciado por este narrador, já que a minha experiência é singular, diferente das demais, se tocando em alguns pontos e se distanciando em muitos outros, mobilizando um pensar mais pelo que difere do que pelo que as identifica e se constituindo em uma narrativa do cuidado.

Essa talvez tenha sido a lógica que aprendi a cultivar na relação com minha filha, a lógica que aprendi com ela e que essas narrativas literárias, documentais ou fílmicas me auxiliaram a ver sentidos outros a essa minha experiência, assim como, imagino, parte daqueles que narram histórias desse tipo, quase autobiográficas, quase ficcionais, quase dramas, quase sem fim, acabam por ela perpassando, ao menos se tiverem alguma abertura e coragem para tal. Embora a coragem aqui seja uma palavra proibida porque é uma narrativa muito mais da insegurança, pensem apenas que aqui se expressa uma tentativa controlar um medo incontido por uma escrita ou por um ensaio similar a outras narrativas, pois, ninguém sabe quantas voltas precisei dar em torno de meu próprio eixo para estar aqui e agora lhes escrevendo, não sem algum receio, alguma vergonha de expor-me e, enfim, disso tudo que caracteriza uma narrativa em que se é testemunho, nos termos de Agamben (2005).

$$
* * *
$$

Na gravidez de minha esposa, acompanhei todos os exames de perto. Estava sendo gestada em ideia e imaginação aquela que, depois que ficamos sabendo o gênero, seria a nossa filha. Muitas conversas ao pé-de-ouvido na barriga, enquanto mexia e remexia sem parar quando ouvia nossas vozes. Mais do que uma filha gestada na barriga da mãe, depois fui entender, uma ideia de filha estava sendo gerada. Em tal gestação, como diz Peju (2004), eu era apenas o pai, aquele que circula em volta da mãe e do bebe, sem poder de senti-lo fisicamente, sentindo-se prescindível e, no máximo, capaz de sentir toda aquela movimentação numa barriga alheia. Por sua vez, a mãe que traz no ventre a criança, parece também gestá-la duplamente, formando também imagens com as quais, mais tarde, no nascimento, poderá comparar com o bebe real. Assim, minha esposa e eu, de modo distinto, imaginávamos uma feição, um rosto, muito, muito conhecido na ânsia de aguardar o nascimento e ver uma face e um corpo reais.

Talvez, a única coisa certa é que a amaríamos como fosse, como concretamente se apresentasse a nós: gravidez desejada, filha muito amada! Este foi um mantra recitado em minha cabeça, inúmeras vezes, como uma espécie de preparo desse tão aguardado nascimento. Finalmente, o nascimento veio. Um dia antes, quando fomos ao ginecologista, ele disse se queríamos que o parto fosse naquela noite ou no dia seguinte. Pegou-nos totalmente de surpresa. 0 parto foi no dia seguinte. Depois da notícia do nascimento esta era a segunda vez que sentia medo diante do parto que se aproximava. Achava estranho que, após a ausculta do coração da bebe (já chamada pelo nome), o médico tenha marcado tão rapidamente a cesariana, mas, enfim, estava lá, com máquina e tudo para filmar

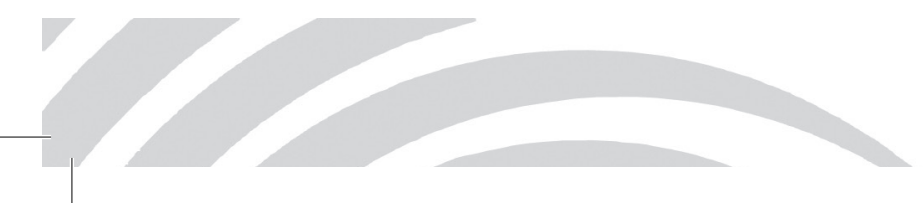


nascimento tão esperado e alguma consternação com o equipamento na sala de cirurgia.

Os médicos e enfermeira já habituados pouco se importavam. Uma rápida conversa com o médico enquanto vestíamos os aventais, na mesma sala, onde contou rapidamente sobre o tempo de profissão e o número de crianças que havia ajudado a trazer ao mundo, logo, estávamos todos lá prontos para mais uma chegada para a equipe e, especialmente, para um acontecimento em minha vida e na de minha esposa. Filmei tudo o que pude. Vi aquele nenê roxinho sair da barriga da mãe, sem muito choro, senti a emoção profunda de ver chegar ao mundo minha filha, embora um pouco atrapalhado com a câmera e com as lágrimas. Pude tocá-la, depois que tocou a mãe pela primeira vez e, logo, nos foi retirada. Toques inesquecíveis esses que são os primeiros e que ficam marcados em nossa memória. Estranhei tanto silêncio no nascimento, mais ainda certo olhar cauteloso dos médicos que a cercavam, especialmente, do pediatra que até hoje à acompanha. Só ouvi, enquanto filmava, que o cordão estava quase seco e o parto havia sido na hora certa: um dizendo para o outro, vamos encaminhar para exames o cordão. Mesmo assim, pensei comigo que bom... a pressa da consulta ao parto foi boa.

Enquanto minha esposa era levada para outra sala, me aproximei do pediatra e perguntei se estava tudo bem e, então, ele me chamou de lado, para perto de minha filha. Disse-me mais ou menos o seguinte: "Ela nasceu bem fisicamente, com 59 cem, 2 kg 800, apgar 10/9 excelente, porém, há uma suspeita de que tenha nascido com Trissomia do 21 invertido". A suspeita partia de alguns traços físicos como a forma dos dedos e dos olhos, a localização das orelhas, entre outras, e, o que viemos a saber mais tarde, um sopro cardíaco irregular.

Fiquei mudo, um buraco se abriu sob os meus pés e, pelo que me lembro, a única coisa que perguntei foi se correia risco de morte. A resposta foi a de que não e de que deveria esperar mais um dia para que minha esposa se recuperasse para que pudesse contar-lhe o que estava ocorrendo. Pensei comigo: como pode me dizer algo desse tipo, sem nos conhecer e sem saber que compartíamos tudo um com o outro. Dei alguns passos sem saber o que fazer, coberto de lágrimas e tendo que me conter aparentemente para que encontrasse a minha esposa, e não a preocupasse de imediato, ao menos até chegar ao quarto, quando lhe contaria. Entre o período em que ela aguardava para dar de mamar à nossa filha e o momento de ir para o quarto, fiquei desfilando meu sorriso amarelo e fazendo algo que nunca soube fazer bem: enganar.
Antes de ir ao quarto, num dos momentos que pude me afastar, encontrei o obstetra que tentou me tranquilizar e na sua plácida humanidade contou algumas histórias, dizendo que isso ocorre em poucos casos que tiveram o acompanhamento que tivemos, como também poderia ser o contrário. Ouvi com atenção tudo aquilo e disse-lhe que não omitiria nada de minha esposa, no que concordou prontamente comigo.

Recentemente, em uma consulta, o mesmo obstetra revelou a sua admiração pelo modo como, desde o princípio, lidamos com a situação e como cuidamos de nossa filha, o que nos encheu de orgulho, porém, não era essa segurança, tampouco sentimento que tínhamos na ocasião. Aliás, os fantasmas que passaram pela minha cabeça na ocasião foram os mais assombrosos. Faltava familiaridade, distinta do que aquela que tinha com a ideia gestada de uma filha ideal, perfeita e, sobretudo, normal... palavra que ressoava na minha cabeça como a de alguém que precisava expiar uma culpa, ainda que não soubesse de quê.

Ainda na enfermaria próxima à sala de cirurgia, como minha filha não pegou imediatamente no peito, algo que demoraria mais algum tempo (duas ou três semanas), uma enfermeira recomendou que fôssemos levados ao quarto, onde receberíamos o auxílio de uma enfermeira para que minha esposa retirasse o leite para amamenta-la. Aguardei mais um pouco -quase uma eternidade de contenção e sofrimento-, enquanto a enfermeira ajudava a minha esposa com a ordenha, pedi-lhes para sair, dando uma desculpa qualquer.

Chorei como uma criança na porta do hospital. Chegara a hora de enfrentar pela primeira vez os fantasmas. Indagava-me o que estava acontecendo e a pergunta que ecoava em minha cabeça era o porquê minha filha teria nascido com um "problema" (ainda não sabia que trissomia e síndrome de Down eram a mesma coisa, embora imaginasse vagamente, mas resistisse) e por que nós, minha esposa e eu, seríamos os escolhidos para enfrenta-lo. Quantas vezes, depois, nos meses que se seguiram, não fiz essa pergunta. Um pouco como algo que é uma característica pessoal, esse tom dramático de que os problemas são sempre maiores quando são meus, nossos talvez, mas, agora, pensava eu, tinha motivo para dramatizar. A culpa não foi expiada por ela, mas também deixou de existir muito rapidamente... já não sentia culpa, somente medo do que teria que enfrentar pela frente. Mas medo de quê eu tinha, penso eu, hoje? Talvez, de ver se perder uma ideia de filha, diante de uma filha real, um luto que alguns pais vivem ao longo dos anos e outros, como eu, vivem em pouquíssimo 
Algumas enfermeiras disseram-nos, quando nos viram chorar ainda na maternidade: "crianças como essas só nascem para pais especiais como vocês, que se amam e que poderão lhes dar uma boa família”.

Entendia o gesto de solidariedade embutido em cada palavra, mas não nos sentíamos especiais dessa forma, ao contrário, e falamos isso para muita gente que veio nos consolar com essa frase, o que nos preocupava não era se seríamos ou não especiais, mas se estaríamos à altura de ter alguém como nossa filha. Isto, sim, era o que nos pegava e nos amedrontava. Algo que somente foi superado na convivência com ela e, gradativamente, fomos nos sentindo mais seguros como pais, obviamente, com todas incertezas que aturdem os espécimes desse gênero, em relação à educação, ao futuro...ah, o futuro!

Aos poucos, minha razão e o meu inconsciente tramaram-me peças incríveis, ajudando-me a perceber que tinha passado uma vida inteira me preparando para esse acontecimento que vivia nesse momento, por mais que não me sentisse preparado para tal. Vinham em minha memória as aulas de Educação Física que ministrava para classes especiais. Os nomes das crianças com quem trabalhei brotavam em minha cabeça, juntamente com seus rostos e com a pergunta: onde estão Janaína, Rodrigo, José Fernandes, Manoel, dentre tantos outros, cujos traços fisionômicos e gestualidade, se mostravam na feição de minha filha ou, melhor, em uma imagem do que ela seria no futuro.

Algo parecido se passava com a minha esposa. Há pouco tempo havia orientado um grupo de pais de crianças autistas, com trissomia e outras síndromes no Centro de Estudos em Educação e Saúde da UNESP, onde atuava como voluntária. Tinha certa experiência com esse trabalho de orientação psicológica desde 1997. Coincidentemente, os discursos que ouvia aos poucos ressoavam, até porque uma das funcionárias do hospital que servia o quarto em que estávamos instalados fazia parte desse grupo e, quando se aproximava, sem que o soubesse ativava essa poderosa memória inconsciente.

Suspeitava que minha aproximação da filosofia da diferença e temas correlatos não teria sido por acaso, assim como a convivência com meu supervisor de pós-doutorado que virou um grande amigo, daqueles que escolhemos como irmão, que tem um filho com necessidades especial, com o qual convivi por algum tempo. Nesses momentos acreditamos em tudo que queremos e que convém, podem dizer alguns, mas também em tudo que faz algum sentido e que nos faz sentir mais fortes, potentes e, quem sabe, a altura do que nos passa, por mais difícil que isso seja. E, posso dizer, buscava um sentido para o que se passava, tentando tornar útil tudo aquilo que lera, vira e experimentara. Dava-me conta em relação ao que tentei compreender, sem muito êxito, em Deleuze (2000) e que agora encontrava diante de mim, com um nascimento, o de minha filha: um acontecimento. Por sua vez, essa noção me remetia à conferência proferida por um grande amigo (o mesmo que foi meu supervisor de pós-doutorado) em um dos eventos que organizei e que minha esposa -com mais ou menos seis meses de gravidez- e eu ouvimos com muito encantamento como uma celebração da vida, mesmo no momento em que tanto falava da morte (Bárcena, 2010).

Enquanto elaborava o luto de uma ideia de filha convivendo com uma criança real e percebendo que esta dependia de cuidados especiais, começava a sentir essa celebração da vida com muito mais vigor do que qualquer representação ou norma, porque proveniente de um encontro e, principalmente, de uma experiência com alguém que me surpreendia e, na relação desarmada com ela, fazia me ver o quanto podia esperar dela, de seu nascimento. Percebia, assim, o quanto me equivocara em relação ao nascimento de minha filha, pois, a promessa de novidade que agora via era mais alvissareira do que a de qualquer outra, implicava numa mudança efetiva se não do mundo, ao menos minha.

Quando li O filho eterno de Ricardo Tezza (2008), minha filha tinha acabado de nascer e estávamos ainda averiguando com os cardiologistas se teria ou não que se submeter a uma cirurgia para a correção de um defeito cardíaco congênito nas valvas e, segundo dizem os médicos, comum em parte das crianças que nascem com Síndrome de Down.

Não sei se essas foram imagens que me confortaram diante de um espírito tão pouco afeito à religiosidade ou se existe uma racionalidade outra, como depois li nas obras de Foucault (2004) sobre os estoicos. 0 que sei é que tudo aquilo que estava incorporado a minha experiência me ajudaram a enfrentar essa situação e assumir minha filha não mais como uma ideia, mas uma criança real, que se apresentava diante de mim e, como todas as outras, diferente. Em um único gesto, o do nascimento, minha filha me ensinou o que há uma década vinha tentando aprender com a diferença, tarefa que desde então me dedico todo dia, no exercício da paternidade, surpreendendo e, principalmente, sendo surpreendido por ela.

Esse meu aprendizado se deve também à minha esposa que, diferentemente de mim, com sua percepção aguda descobriu que é melhor deixar que nossa filha mostre-nos as suas potencialidades, até onde

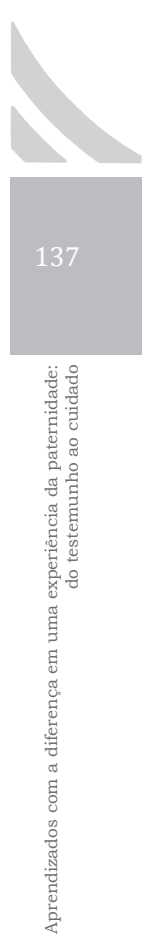


pode chegar, do que acreditar na norma instituída e nas teorias de desenvolvimento infantil, que a concebe de modo indiferente. Diferentemente do que narrado em $O$ Filho Eterno de Ricardo Tezza (2008), optamos por não entrar na corrida pela normalidade, como um déficit a ser superado em cada atividade e, enfim, chegar a ser "normal", talvez, neste caso e em muitos outros, podemos dizer que não é o que queremos para ela e teremos que lutar contra aqueles que querem julgá-la dessa forma.

Resolvemos, sob este aspecto, inverter um pouco as regras desse jogo e olhar mais para ela do que o que se espera para uma criança como ela ou na faixa de desenvolvimento dela, reconhecendo aí uma potencialidade que nos indicará como e o que fazer. E, desde então, temos visto como tem potencialidade - para usar uma expressão que alguns amigos que trabalham com Educação Especial utilizaram na primeira vez que a viram. Isso porque percebemos que, embora desde os dois meses de vida faça estimulação precoce, há uma coisa que é da própria Ana Sophia: um brilho nos olhos que se percebe pulsar a vida e uma força que se vê em cada gesto.

Se isso foi perceptível logo nos primeiros meses, teríamos ainda muito que descobrir e o que enfrentar com ela. Às vezes, ouvindo absurdos de pais de crianças com alguma necessidade especial que, constantemente, nos interpelavam para dizer que tinham "uma criança igual a essa em casa", até que aprendemos a responder que "não, não, igual a ela não existia, muito menos estava em casa alheia". Outras vezes perguntavam se não teríamos mais filhos, dizendo de sua própria experiência que só se tranquilizaram depois que o filho ou a filha seguinte nasceu normal, sem se importar se o assunto da normalidade nos incomodava ou não. Isso nos afastou um pouco de reuniões de pais, pois, a conversa que se vê circular em geral nesses ambientes é acerca da normalidade -chamam médicos e especialistas para proferirem palestras acerca de um saber que poderá fazer com que nossos filhos cheguem o mais próximo possível de uma linha chamada normal.

O que sentia e sinto falta é de ouvir como foram pais e mães de crianças e jovens com necessidades especiais, a narrativa de experiências de maternidade e paternidade reais, assim como ouvir essas mesmas crianças e jovens, quem sabe, para conhecer melhor o mundo que vivem e a vida que levam, como mostra brilhantemente o documentário de Evaldo Mocarzel Do luto à luta. Diferentemente de ter buscado esse documentário como fiz com o livro de Tezza (2008), demorei muito para assisti-lo. Fui a um congresso em que esse documentário estava sendo apresentado em seu circuito cinematográfico e arrumei uma série de subterfúgios para não vê-lo. Depois, criei coragem e o comprei. Ficou muito tempo guardado, até que um dia, após ter assistido uma parte do documentário na TV, sem saber o que era, fui assisti-lo.

0 reencontro da coragem para assistir o filme ocorreu após um momento que havia tentado mobilizar bastante essa virtude para enfrentar um problema bem mais delicado do que os meus medos e uma situação que colocava em risco a vida de minha filha. Ana Sophia tinha nascido com um problema cardíaco congênito, um sopro ou, na linguagem médica, um defeito nas valvas. Minha esposa e eu andamos de médico em médico em busca de uma resposta que indicasse a desnecessidade de correção cirúrgica. Contudo, todos davam a resposta era quase a mesma, a cirurgia era necessária e deveria ocorrer no quinto mês de vida de nossa filha. Em cada vez, foi como se fosse a primeira, aquelas palavras chegavam aos meus ouvidos em um tom ensurdecedor, que me levavam ao desespero, e para fugir disso, punha minha imaginação para funcionar, como faz toda criança que, ao se proteger do mundo, cria o seu em que coisas impossíveis podem acontecer.

Gostaria de trocar de lugar com ela, mas não era possível: a síndrome ficou uma coisa muito pequena diante da cirurgia que iria enfrentar. Isso ocorreu no mesmo período em que recebi uma notícia profissional das mais gratificantes: tinha conseguido uma bolsa em reconhecimento pelo meu trabalho. Depois de muitos anos de solicitação, recebi essa notícia no momento menos esperado e, poderia dizer com tranquilidade, prescindível. Pensava com a indignação de sempre, sinto orgulho de ter alcançado esse mérito, mas, se fosse possível, trocaria essa conquista profissional, que tanto busquei, por qualquer coisa que amenizasse o sofrimento de minha filha. Contudo, nada disso era possível, só me deu a dimensão de minha impotência sobre o arranjo dessas coisas e que uma coisa nada tinha a ver com outra, salvo pelo fato de perceber que o que dava valor atualmente não era mais o mesmo nem se restringia ao reconhecimento pelo meu mérito profissional. Agora, o que estava em risco era a vida de minha filha.

O temor em perdê-la foi algo que me acompanhou nesse período, devo assumir, ao ponto de resistir a tudo que me afastasse muito de minha filha, ao mesmo tempo em que as imagens que habitavam minha cabeça e tentavam reverter o estado de impotência sentida ocupavam meus pensamentos: os problemas profissionais ficaram pequenos. Dos problemas aos compromissos já assumidos, o que me importava era ver minha filha bem, levando uma vida sem limitações

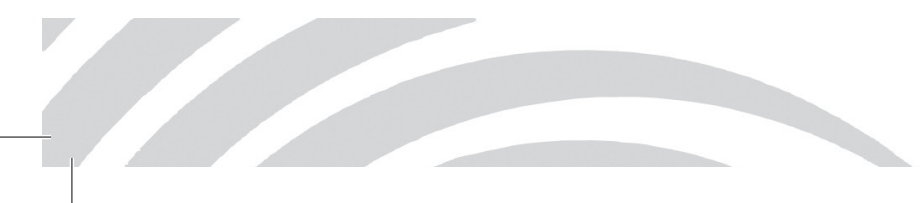


e livre do risco de morte, algo que fez com que redimensionasse minha vida e as pretensões na carreira a qual havia escolhido.

Foi no vínculo que estabeleci com ela, o da paternidade mesma, construído no dia-a-dia, que me senti mais apto para enfrentar a situação e para confiar profundamente nela, na vontade de vida que lhe saltava os olhos. Em contrapartida, encontrei no gesto de muitas pessoas da família, de amigos e de colegas de trabalho de vários lugares, estados e países uma solidariedade tamanha e sincera, que me fez voltar acreditar que, se a vida intelectual não era mais a mesma, ainda havia nela pessoas que a habitavam. Via se processar uma esperança na universidade e na política acadêmica, ao mesmo tempo em que me sentida pessoalmente arrasado, limitado, mobilizando quase todas minhas forças para estar ao lado de minha esposa e acompanhar a minha filha.

A aflição de minha esposa e a minha eram tanta que, na antessala de cirurgia, momentos antes de entrega-la a uma competente equipe de cirurgiões, em São Paulo, Ana Sophia nos olhou com tanta tranquilidade, enquanto nos debulhávamos em lágrimas, que nos trouxe uma profunda esperança na sua recuperação. Agiu como se tudo passaria bem e a pulsão de vida que brotava em seu olhar nos inspirou a coragem exigida para que enfrentássemos a situação. No período em que esteve internada no Centro de Terapia Intensiva, ouvimos outras histórias, algumas mais complicadas do que a de nossa filha, outras sem diagnóstico, que nos fizeram olhar um pouco mais a nossa volta. Sentíamos certo alívio por ela ter uma síndrome tão estudada e conhecida, que poderia de agora em diante ter os mesmos problemas de todos os pais, se tudo corresse bem na cirurgia. Efetivamente, tudo correu bem. Em poucos dias ela saiu do CTI, em seguida ficou mais um dia no quarto e, por fim, voltou para a casa, sendo que hoje está totalmente liberada para fazer o que toda criança faz, correr, brincar, nadar, e como gosta de nadar.

Dessa experiência ficaram algumas marcas físicas nela: certa resistência a hospitais e pessoas de branco. Em nós, imagens de alguém tão pequena tendo que passar pelo que passou, as noites em claro no CTI, as crises de abstinência de remédios e a agitação constante das noites. Desde então os problemas passaram a ter dimensão que possuem, ao menos assim os julgo, dando-lhes o tamanho que têm. Passei também a desempenhar várias tarefas profissionais ao mesmo tempo e fazer as coisas com um pouco mais de presteza, para que pudesse dedicar maior tempo a minha filha. Não que hoje ela precise desse tempo, mas eu quero dispor-me dele para que possa acompanhar cada passo, ver cada conquista e estar presente em sua vida, ao mesmo tempo em que concentro minhas energias em atividades que diga respeito à experiência, à escrita e à docência que permitam um maior engajamento ético e político.

Em relação à família, os primeiros a chegarem ao hospital, inclusive, para ajudar nas duas primeiras semanas foram minha cunhada e meu concunhado. Era perceptível a tensão no ar e, ao mesmo tempo, certa alegria não desfechada. Foi minha cunhada e, depois, minha mãe que acompanharam a saga para fazer ela mamar no peito. Quando conseguiu mamar no peito, comemoramos como uma grande vitória, e assim para cada coisa desde então. 0 primeiro passo, a primeira palavra, o primeiro dia na escola, etc. Desde então, aprendo nessa relação com minha filha a viver a cada dia, comemorando cada conquista e trabalhando para obtê-la, mas, principalmente, aprendo com um tempo diverso, diferente do meu -metido em tantos afazeres e em uma lógica produtivista da universidade- o caro valor da pausa e do ralento, numa melodia que soa bem na medida em que se vê respeitado um ritmo.

Lembro-me quando, após alguns dias na escola, ela aprendeu a diferença entre o rápido e o lento. Começou a cantar uma música lentamente e, de repente, começou gritar e, depois, a cantar mais rápido, mais rápido, numa velocidade extrema que eu mesmo desconhecia. Isso fez com que pensasse: "minha filha estava sendo apresentada ao mundo e, sobretudo, ao tempo que o rege -o da velocidade, e não tinha encontrado qualquer problema nisso, seu ritmo já se misturava com o do mundo, só não sabia julgar se feliz ou infelizmente". De qualquer forma, essas eram as imagens de alguém que sentia vertigem da velocidade do mundo e via que esta não poderia ser refreada por mim, nem pelas novas gerações que lhe faziam coro e tampouco por minha filha que já começava a adentrar a esse ritmo frenético, distorcendo a sua melodia original. Será que era mesmo original ou mais um pressentimento que caia por terra? Não sei qual a resposta a essa pergunta, o que sei é que minha filha cujo diagnóstico dos especialistas supunham uma menina mais lenta, agora, estava cantando na velocidade do mundo. Comecei a ver a captura de um tempo pelo de um mundo absolutamente adulto e massificado, para meu desalento, porém, ainda vejo em bons e longos momentos uma temporalidade que lhe resiste, que caracteriza a infância e que ainda não sei quanto durará.

Enquanto isso, tento dar voz a essa minha experiência da paternidade e da relação com a diferença. Se, em outra ocasião recorri aos documentários de Evaldo Mocarzel e ao livro de Ricardo Tezza (2008) 
para tentar auxiliar a compor meu silêncio e testemunhar minha posição em relação ao assunto (PAGNI, 2010), agora, com esse escrito vejo se abrir outra possibilidade: a de narrar minha própria experiência, testemunhando cada pequeno acontecimento que se passa nessa relação com minha filha e, ao mesmo tempo, engajando-me para lhe auxiliar a ter um lugar no mundo. Mas esse lugar ela terá que conquistar, seguramente, com meu apoio e, muito provavelmente, com meu cuidado, já que essa é minha dívida e, hoje, meu desejo de aprender com a diferença.

\section{Referencias bibliográficas}

Agamben, G. (2005). Homo sacer III: lo que queda de Auschwitz. 2.ed. Valencia: Pre-textos, V. III.

Arendt, H. (1996). La crisis en la educación. En Entre el pasado y el futuro. Barcelona: Península, p. 185-208.

Bárcena, F. (2010). A dignidade de um acontecimento. Sobre a pedagogia da despedida. En Pagni, P. A.; Gelamo, R.P. Experiência, Educação e Contemporaneidade. São Paulo/Marília: Cultura Acadêmica/Poïesis.

Deleuze, G. (2000). Lógica do sentido. 4. ed. São Paulo: Perspectiva.

Foucault, M. (2004). A Hermenêutica do Sujeito. São Paulo: Martins Fontes.

Lyotard, J. F. (1997). O inumano: considerações sobre o tempo. 2.ed. Lisboa: Editorial Estampa.

Pagni, P.A. (2010). Um ensaio sobre a experiência, a infância do pensamento e a ética do cuidado: pensar a diferença e a alteridade na práxis educativa. In: Kohan, W.O. Devircriança da filosofia. Belo Horizonte: Autêntica.

Péju, P. (2004). Nacimientos. Salamanca: Ediciones Tempora.

Tezza, R. (2008). O filho eterno. 6. ed. Rio de Janeiro: Record. 